\title{
NOS TEMPOS DA MUDANÇA \\ ABERTURAS POSSÍVEIS, ACORDOS REVISITADOS E CONCEPÇÕES SOBRE CONSUMO $(1808-1821)^{1}$
}

\author{
In the Times of Change \\ Possible openings, agreements revisited and \\ conceptions about consumption (1808-1821)
}

\author{
Rosângela Ferreira Leite*
}

\begin{abstract}
RESUMO
Este artigo analisa as relações diplomáticas entre Portugal e GrãBretanha, no período entre 1808 e 1821. Numa primeira ordem de eventos, consideramos as aberturas comerciais possíveis e as leituras que os agentes de época fizeram do termo monopólio. Já na segunda parte, salientamos as revisões dos acordos e os rumos tomados a partir do Congresso de Viena. Uma das modalidades de mudança, nesse grande quadro de transformações, foi a alteração das percepções e práticas acerca do consumo.
\end{abstract}

Palavras-chave: consumo; monopólio; diplomacia.

\begin{abstract}
This article analyzes the diplomatic disputes between Portugal and Great Britain in the period between 1808 and 1821. In the first part of this text we analyze the possible commercial openings and the readings that the agents of time made of the term monopoly. In the second part of this article we discuss the revisions of the agreements and the directions taken from the Vienna Congress. One part of this change was the alteration of perceptions and practices about consumption.
\end{abstract}

\footnotetext{
1 Este artigo é parte de pesquisa que realizo sob financiamento do CNPq.

* Doutora em História, professora de História Contemporânea, na UNIFESP, Guarulhos.
} 
Keywords: consume; monopoly; diplomacy.

\section{Introdução}

No início do século XIX, as transformações geopolíticas e os movimentos que gestaram a Revolução Industrial $^{2}$ reescreveram a história das doutrinas econômicas. Ao olhar para o passado, os homens e mulheres oitocentistas buscavam uma unidade de pensamento e reinventavam, cada qual ao seu modo, uma linha de atuação do Estado. ${ }^{3}$

Quando a Corte Portuguesa desembarcou na cidade do Rio de Janeiro, em 8 de março de 1808, tinha por tarefa preservar seu império, reconhecer as demandas dos agentes locais e sustentar a aliança com a casa dos Hanôvers. Formou-se, desde então, um complicado jogo entre plenipotenciários das duas nações. As construções dos acordos passaram, inevitavelmente, pela reinterpretação do pensamento político-econômico, testemunhando a feitura de um universo público que abarcava novas maneiras de apreender os objetos. ${ }^{4}$

2 Evita-se, neste texto, atribuir ao início do século XIX um extenso desenvolvimento científico ou dos padrões de vida. Sob qualquer caminho historiográfico, no entanto, é patente reconhecer que houve a difusão da produção, comércio e transformação da matéria-prima algodão, e que este momento foi crucial para as transformações em curso e incremento das invenções, ou novos usos dos dispositivos tecnológicos já existentes. Também é patente que essas condições se deram na Grã-Bretanha, que no início do século XIX combinava circunstâncias excepcionalmente favoráveis para o florescimento de uma plena sociedade capitalista. HOBSBAWM, 2014.

3 Não retomaremos neste artigo os conceitos jurídicos de mercantilismo que remontam à Idade Média. Interessam-nos as repercussões desses conceitos na conformação político-econômica do Brasil no início do século XIX. A referência primordial para este caminho de análise é, sem dúvida, o texto clássico de Eli HECKSCHER (1943).

4 Nosso caminho de pesquisa privilegia as alterações das ações de Estado e as construções e/ou manutenções dos costumes como interfaces de uma mesma moeda. Por um lado, fincamos o pé na literatura que reconhece que o concerto diplomático permitiu as atuações das coroas da Grã-Bretanha e Portugal em consonância com as realidades das partes do Brasil. Uma vez que nos interessa o fenômeno da entrada de bens, levantamos questionamentos sobre as possibilidades de diversificação de produtos diante de um mercado consumidor limitado. As reflexões sobre a mudança nas percepções de consumo como parte das transformações políticas acerca das mercadorias, no início do século XIX, podem ser encontradas em William REDDY 
Este artigo tem por objetivo acompanhar os usos do termo monopólio, no início do século XIX, nas partes do Brasil. É certo que a ênfase recai sobre a Corte do Rio de Janeiro. No entanto, outras regiões serão mencionadas ao longo desta análise.

Busca-se compreender a relação entre ação política e vida material. Esta perspectiva parte do escopo teórico que acentua a passagem do século XVIII para o XIX como momento de construção, também, de uma silenciosa revolução nos sistemas domésticos, nas formas de vida e, por consequência, nas aspirações de consumo (DE VRIES, 2008). As "consciências costumeiras" e as normatividades são apresentadas como interfaces de uma mesma moeda. ${ }^{5}$

A modernidade da ação diplomática portuguesa, por um lado, e as pressões inglesas, por outro, produziram um quadro cuja rápida transformação no mundo das mercadorias caminhou ao lado de uma lenta dissolução das práticas tradicionais de comércio. As novas pautas de consumo, ${ }^{6}$ que surgiram no período, foram resultados destes equilíbrios.

\section{Aberturas Possiveis}

O Tratado de Comércio Entre Portugal e Inglaterra, de 1810 (BRASIL, 1890, p. 52), representou um marco na supressão do exclusivo colonial português sobre sua principal colônia. Contudo, as manutenções da monarquia e do império português revelaram que o equilíbrio entre monopólio, distensão de controle e papel do Estado

(2008, p. 329-357) e em WILLIAMS (1982). Por outro turno, Jorge PEDREIRA (1994) ressaltou a especificidade do "pensamento público" sobre o consumo como parte de uma tradição portuguesa de cultura comercial.

$5 \mathrm{Na}$ interface da lei com a prática, situamos o costume. Os costumes podem ser de ordem recente ou, inscritos na tradição. Interessa, no escopo deste artigo, compreender a relação entre construção de costume, surgimento de práticas e apreensões acerca do consumo. THOMPSON, 1988.

6 Compreende-se por "novas pautas de consumo" a disposição de novos produtos na Praça do Rio de Janeiro, bem como suas formas de usos, absorções possíveis e releituras dos objetos. Na historiografia Espanhola este termo tem ganhado bastante relevância para designar as formas de entrada de novos produtos às realidades urbanas no final do antigo regime. Veja-se a este respeito: NAVARRO, 2011; CLAVERÍAS, 2002. 
tivera que ser contrabalanceado em meio a inúmeras dissidências e reclamações. Esse jogo não era novo e acompanhava o próprio princípio do monopólio. $\mathrm{Na}$ Inglaterra, o monopólio baseado no privilégio real era rechaçado; os monopólios criados por leis do Parlamento eram respeitados; as corporações profissionais eram (quase sempre) defendidas; e o direito consuetudinário, resguardado. Diante dessa miríade de arranjos, interessa compreender o momento em que o princípio econômico se deparou com uma condição política especial para o seu manejo e quais foram os resultados possíveis.

A constante dicotomia que se estabelece entre abertura comercial e fins dos privilégios de antigo regime, embora inelutável, não é suficiente à seara do consumo. A principal colônia do império português, passou, nas duas primeiras décadas do século XIX, por alterações nos hábitos das pessoas e redefinição do universo político. Tratava-se de um momento de construções de legitimidades, produções de apagamentos e interpretações diversas à letra da lei. Acompanhar as releituras do termo monopólio permite vislumbrar este ziguezague:

\begin{abstract}
Parece que o governo português se opõe à necessária abolição dos diversos monopólios por duas razões. A primeira que no Tratado se não estipulou especialmente $\mathrm{e}$ por nome a extensão de cada um deles. A segunda, que é contra o decoro de SAR O príncipe do Brasil de consentir nesta resolução em consequência dela lhe ser pedida por uma potência estrangeira (MISSÕES, 1812, p. 103).
\end{abstract}

O texto em questão era o Tratado de Comércio de 1810. A tese da diplomacia portuguesa foi a de que não estava contida, na letra da lei, a demarcação de todos os pontos do comércio. Esta omissão abriria brecha à autonomia política do Príncipe Regente. Nos escritos diplomáticos, a soberania aparecia como "decoro" do monarca em curvar-se às resoluções externas. Até 1812 este argumento funcionou, em alguma medida, para o arranjo do comércio português. Enquanto os conflitos na Europa representaram ameaça ao poderio de Jorge III, a diplomacia britânica foi cuidadosa em suas críticas às práticas 
portuguesas. Argumentava-se que, naquele momento, a legitimidade do soberano da Casa de Bragança era fundamental para o concerto político da Europa (CANNING, 1808, p. 04).

À proporção que os plenipotenciários portugueses aprimoravam seus argumentos, na Praça do Rio de Janeiro formavase um verdadeiro quartel-general diplomático e do comércio, chefiado por Percy Clinton Sydney Smythe, mais conhecido como Lord Strangford. A manutenção de regras e conduta de Antigo Regime, que se contrapunham às intenções do Tratado de Comércio, criava uma situação por meio da qual os valores, consubstanciados em símbolos de uma longa tradição, eram adotados, numa certa versão, em um contexto completamente novo. Assim, as normas que por muito tempo funcionaram como reguladoras de uma relação social específica, nesse novo contexto, precisavam ser explicadas: $O$ Tratado não havia estipulado a extensão e a natureza do monopólio sobre cada produto e região e Sua Alteza Real, o Príncipe Regente, por seu "decoro e honra", podia beneficiar seus súditos, ao mesmo tempo em que abria os portos às nações amigas. ${ }^{7}$

Nessa mesma perspectiva, D. João procurava acalmar os ânimos dos comerciantes que permaneceram em Portugal, indicando que suas manufaturas e bens agrícolas estariam protegidos contra a concorrência desleal da Grã-Bretanha. Promessa difícil de cumprir, mas que assinalava, todavia, esforço de independência e oferecimento de benesses aos vassalos de um soberano ausente (NOTAS, 1808). A estratégia de tatear diante das incertezas era prova de uma perspicaz visão de conjunto:

O primeiro põe em questão a utilidade de se fazer no momento atual Tratados de Comércio com as nações aliadas.

A solução do quesito parece de primeira intuição pela parte negativa, quando a prudência, ainda sem vir em linha de conta as mais circunstâncias que aponta a

7 Notas Expedidas. Rio de Janeiro: Arquivo Histórico do Itamaraty, 1808-1810. 
representação, e o muito que se pode dizer parece exigir que Nós não empenhemos em Tratado algum definitivo, enquanto o estado violentíssimo, em que se acha a Europa, não mudar; podendo com essa mudança, que de necessidade deve suceder, e dentro de poucos anos, voltar-se muito em nosso dano, impossibilitando-nos para então tirarmos o partido competente, e talvez motivando-nos guerras (RESPOSTA, 1808, p. 01). (grifos meus).

Do ponto de vista político, os Tratados amainavam as contradições da conjuntura de guerra; mas não resolviam todos os problemas.

Era necessário traçar novos sentidos e limites à ação comercial e ao papel do Estado. Na Grã-Bretanha, em 1813, na Câmara dos Lordes, foi travado um longo debate sobre o monopólio da Companhia das Índias Orientais. Em meio a essa contenda, um dos interlocutores definiu que:

Outra questão importante foi o poder militar na Índia que, por meio de critério político e gestão, tinha atingido a sua atual condição formidável, mas que por qualquer infelicidade ou direção colocou-se suscetível de decepcionar todas as esperanças que dele dependem desse assunto, o seu senhorio voltado para o comércio da Índia, que, através da renovação da carta em sua forma atual, abriria todas as suas vantagens para os países em reinar em detrimento dos comerciantes Ingleses. Isso não só será o caso que diz respeito ao nosso assentamento na Índia, mas a China, e todas as ilhas recém-adquiridas, que rogavam seus senhores a analisar o efeito do monopólio na prevenção de todos os benefícios de um comércio aberto entre esses países e os portos da América do Sul, que, seja qual for o resultado do contexto presente na Europa, seria, com toda a probabilidade definidas em breve em favor da abertura de um comércio em geral (THE PARLIAMENTARY, 1813, p. 231). 
Torna-se patente, no discurso acima citado, a relação entre as diferentes formas de administração e contatos comerciais. Conquanto o monopólio fosse reconhecido, pelos agentes de época, como fundamental para a instalação da política colonial na Índia, sobressaía o argumento de não se usar aquela estratégia de maneira contínua. Para o expositor, as práticas de monopólio se deparavam com um novo contexto internacional, marcado pelo comércio com os países e portos da América do Sul.

Apoiar a Companhia de Comércio das Índias e, ao mesmo tempo, ampliar a atuação sobre a Índia e sobre a China foi a saída proposta naquele contexto. Tratava-se de um caminho que comportava estratégias variadas. ${ }^{8}$ Essa variedade encontrou um campo fértil à sua acomodação. Parte do sucesso se deveu ao próprio incremento dos dispositivos repressivos. Nesse período, quando o clima de insegurança social crescia em diferentes pontos da GrãBretanha, - como as manifestações dos quebradores de máquinas - as reações se ampliaram e o aprimoramento da militarização e do controle indicava para a construção de uma polícia política eficiente (NEAL, 1990, p. 116). Em 1819, o massacre de Peterloo foi um marco no processo de consolidação desse equilíbrio baseado na força. Nesse mesmo momento, firmava-se um grande corpo militar de carreira, com patentes adquiridas ao longo das guerras napoleônicas. Este feixe de ideias começava a ser amarrado pelas cordas da paz e do comércio (POLANYI, 2012, p. 16).

Quando os lordes reunidos no Parlamento debateram os sentidos do império e suas formas de administração e poder político, tratava-se de uma reflexão sobre a extensão, mas, também, sobre os limites daquele Estado. O liberalismo, muito embora apresentasse traços constitutivos, não era a única, nem era (ainda) a expressão econômica mais importante. As reações daqueles homens assinalavam os esforços de integração das massas trabalhadoras, de

8 Na Câmara dos Comuns, durante todo o ano de 1813, a Companhia das Índias e a organização do comércio também foram temas discutidos com veemência. THE PARLIAMENTARY, p. 227, 285, 351, 414, 471, 671 e 789. 
organização de diferentes partes do comércio e de construção de uma viva oposição ao racionalismo da ilustração. ${ }^{9}$

Naquela conjuntura, abundaram os mecanismos de repressão sobre os trabalhadores e, na esteira do declínio do poderio de Napoleão, o governo britânico teve condições para respaldar o controle indireto, por meio da renovação do Conselho da Companhia das Índias. No entanto, ao longo do momento mais acentuado de guerras, os comerciantes tinham expandido seus negócios. Quando o Estado novamente se fez presente, esses homens ligados ao trato manifestaram descontentamento com as restrições impostas pela Coroa Britânica. Os fabricantes de Lancashire formaram um dos grupos que reivindicou a extensão de seus próprios mercados na Índia (WALLERSTEIN, 1999, p. 257).

Em Portugal e no Rio de Janeiro a colisão entre autoridades portuguesas e britânicas era assunto recorrente (SMYTHE, 1812, p. 28). Comerciantes britânicos reivindicavam uma abertura irrestrita e rogavam por comerciar sabão, tecidos, aguardente, cartas, vinhos. Já os portugueses, partindo das mesmas leis, compreendiam a legitimidade do monopólio da Companhia do Douro e exigiam deferência às práticas comerciais portuguesas na Índia (LEGAÇÕ̃ES, 1808). Foi em meio a essas leituras diversas à letra da lei que surgiram novas maneiras de apreender as mercadorias. ${ }^{10}$

\section{Acordos Revisitados}

9 Do ponto de vista da História do Consumo, identifica-se que a bandeira de "livre comércio" esteve aliada a conceitos de progresso, paz e civilização. Este arcabouço moralizador foi fundamental à construção de uma ideia de "cidadão consumidor". TRENTMANN, 2009.

10 Nossa escolha pelo caminho que assinala a história da apreensão de novas mercadorias se aproxima da ideia de novas pautas de consumo. A palavra pauta vem do latim pactus, que significa fixado, fincado; o pactum também pode ser lido como criação de convenção. Longe das perspectivas que reconhecem as mercadorias como detentoras de vida social em si, procura-se ressaltar, seguindo a historiografia espanhola e a percepção de costume em Thompson, como as leis e os usos costumeiros foram criando convenções às coisas, num movimento constante de acordos, disputas e dissidências. FATTACCIU, 2011, p. 153-171; THOMPSON, 1991. 
O fim das Guerras Napoleônicas e o Congresso de Viena alteraram a condição metrópole-colônia e os arranjos diplomáticos entre Portugal e Grã-Bretanha. O princípio da legitimidade foi instituído com base na premissa da presença da monarquia no reino, o que forcejou a transformação do Brasil em sede do Reino Unido de Portugal, Brasil e Algarve, em 1816. Foi nesse mesmo ano que D. Maria I faleceu, garantindo subida definitiva de D. João ao trono. Em outro plano, o final da Guerra Europeia instituía o comércio livre entre as nações. Por estes motivos, estavam franqueadas as novas rotas comerciais e finalizado o estatuto colonial das partes do Brasil.

O Marquês de Aguiar ${ }^{11}$ teve um papel fundamental nesse novo arranjo diplomático. Sua atuação funcionou no sentido de exigir o cumprimento do Tratado de 1810. Esta reivindicação era, no mínimo, paradoxal. Exatamente no período em que a "aliança entre as nações amigas" não possuía mais valor, a diplomacia portuguesa passou a reivindicá-la!

Um dos esforços empreendidos por Aguiar foi evitar a pilhagem, por parte da Grã-Bretanha, às diferentes partes do Império Português. Estava ocorrendo uma ação deliberada, desde 1814, de tripulações Britânicas que recolhiam madeira em pequenos portos da costa brasileira. Estes eventos tinham apoio de comerciantes e produtores locais. O Marquês de Aguiar combateu prontamente esta ação, acionou o Tratado de Comércio de 1810 e a Ata Final do Congresso de Viena (embora fossem dissonantes) para reconhecer a legitimidade da Coroa Portuguesa sobre toda a sua costa, sobre os diferentes pontos do comércio e sobre a longa relação comercial entre Portugal e Grã-Bretanha.

Da parte dos britânicos, era explícita a intenção de um comércio direto com os agricultores e comerciantes das diferentes partes do Brasil. Desde 1809, George Canning havia mandado uma lista para Strangford indicando suas áreas de interesse: Santos, Salvador, Rio Grande, Pernambuco, Maranhão e Belém (FOREING, 1809 , p. 22). Foi a resoluta ação da diplomacia portuguesa que

11 Fernando José de Portugal e Castro foi o primeiro Conde e o Segundo Marquês de Aguiar. Esteve à frente das negociações diplomáticas com a Grã-Bretanha até 1815, quando foi cedendo espaço ao Conde da Barca. Morreu em janeiro de 1817. Neste texto optou-se por utilizar o "nome" constante nas assinaturas das correspondências diplomáticas. 
impediu este comércio. No entanto, em meio a esta queda de braços, surgiram rotas alternativas: Santos (São Vicente), São Sebastião e Ubatuba aparecem na documentação como lugares de intromissão de navios da Grã-Bretanha (OFÍCIOS, 1822).

Nas diferentes partes do Brasil, as discussões diplomáticas foram convertidas em ações legais ou ilegais ${ }^{12}$. George Canning ressaltava que o problema era a entrega de mercadorias que não chegava a diferentes pontos da vasta costa brasileira. Segundo esta lógica, dever-se-ia avançar. Um navio vazio, uma vez atracado, tornava-se uma embarcação livre para carregamento de madeira. Foi assim que surgiram, na documentação, os pedidos de "liberação de embarcações" de comerciantes ingleses para resgatarem madeira por meio de pequenos portos, sem alfândega (OFÍCIOS, 1822). Em tempo vale esclarecer o nome desta prática: contrabando.

Nesta pesquisa foram levantados os pedidos de liberação de embarcações da Grã-Bretanha - carregadas de madeira - para os portos de São Sebastião, Ubatuba e Santos (São Vicente) (CASTRO, 1815). Mas, o problema era muito maior. A situação ficou tão patente, que em 1817 chegou ao Ministério dos Negócios Estrangeiros e da Guerra um pedido da firma Brown Watson \& Company para exportar madeira ao longo de toda a costa do Brasil. Para responder a esta solicitação, os trabalhos anteriores do Marquês de Aguiar fundamentaram a peça diplomática do Conde da Barca. Segundo o Ministro Interino dos Negócios Estrangeiros e da Guerra, esta solicitação era absurda e violava os princípios definidos na Ata Final do Congresso de Viena, cujas bases se assentavam na soberania das nações. O Conde da Barca também advertia sobre a inoperância de comércio em portos sem alfândega e acrescentava que, uma vez que o princípio da soberania estava garantido pelos trabalhos de Viena, as regras operacionais das relações entre Grã-Bretanha e Reino de Portugal, Brasil e Algarve deveriam ser buscadas no Tratado de Comércio de 19 de fevereiro de 1810.

12 A historiografia que trata do período napoleônico comumente reconhece uma população de exilados e refugiados de guerra. Tratava-se de um momento de grande circulação de pensamentos que se irrompiam pela via individual e carregavam um potencial diversificador, operacionalizando um processo silencioso de apreensão de novas ideias. BLAUFARB, 2005; NEVES, 2008; LEITE, 2012. 
O Marquês de Aguiar e o Conde da Barca ${ }^{13}$ tiveram atuação habilíssima num momento de fragilidade do Império Português. O Tratado de Comércio, que nunca foi seguido à risca, agora era tomado como fonte de legitimidade portuguesa. Uma vez que as Atas de Viena não tinham tocado na extensão do comércio entre diferentes nações, as resoluções anteriores serviriam para suprir a lacuna (CASTRO, 1815).

Desde 1814, o Marquês de Aguiar se encarregou de resposta às reclamações de Lord Strangford, quanto ao tratamento diferenciado à Companhia do Douro. ${ }^{14}$ Vale lembrar que a Companhia do Douro atravessou as guerras napoleônicas, os Tratados de Comércio entre Portugal e Grã-Bretanha e o Congresso de Viena como uma Companhia de caráter monopolista. O sucesso desta empreitada deve ser buscado na capacidade da administração portuguesa de manejar as cordas da diplomacia e de revisitar os acordos, gerando novas formas de atuação: ${ }^{15}$

Poder-se-á objetar que semelhante favor é uma espécie de monopólio, mas como se engrandeceu a Inglaterra pelo memorável Ato de Navegação; como obra ainda hoje e também as mais potências apesar dos escritos dos economistas? (RESPOSTA, 1808, p.10).

13 Antonio de Araújo e Azevedo, a partir de 1816, Conde da Barca, era um diplomata altamente preparado. Sua Biblioteca possuía os títulos mais importantes da época sobre comércio e ciência econômica. O Conde da Barca também estava atualizado com relação aos debates sobre abolição da escravidão. A lista dos livros da biblioteca do Conde da Barca pode ser consultada em: SILVA (1977, p. 115).

14 A Companhia havia sido criada em 1756, no Governo de D. José, por meio de decreto de Sebastião José de Carvalho e Melo, mais tarde Marquês de Pombal. Este alvará permaneceu, entre intempéries e disputas, até 1834. A Partir de 1852 aboliram-se quaisquer direitos da Companhia, mas estabeleceram-se os limites da região da Barra do Douro como produtora exclusiva do vinho que possuía o seu nome.

15 Neste artigo não se enfatiza a história da Companhia do Douro. Este tema, no entanto, perpassa nosso escopo de pesquisa. Considera-se que a marcada experimentação de práticas disformes, por parte da ação do Estado português, gerara frutos duradouros para a formação das nossas práticas de consumo. Tratava-se de um momento de construção de vivências públicas baseadas numa política inovadora, por um lado, e remitente, por outro. Para o Brasil, em período pós-independência, essas construções das leis e dos costumes serão fundamentais para informar sobre as escalas, os bens e os canais de crédito. Cf. SOUZA, 2015. 
Nos escritos "dos economistas" apareciam liberdades para os sujeitos; contudo, as liberdades e eficiências reivindicadas não conformavam uma ordem liberal. Era liberdade para quem podia tê-la e não desatrelava a ação política da atividade econômica; reconhecia a necessidade de abertura aduaneira, mas contava a todo tempo com a reciprocidade e com os privilégios da ordem estamental. Foi no corolário destas ações de Estados, de modificação da economia internacional e das regras e valores de antigo regime (reinventadas nas partes do Brasil), que nasceram as novas percepções sobre os produtos. ${ }^{16}$ Segundo Gaspar Martins Pereira, "Ao delegar grande parte dos poderes de tutela - incluindo jurisdicionais e fiscais - na Companhia, criava-se uma instância reguladora do setor que assumia simultaneamente como representante da região e do Estado" (PEREIRA, 1996, p. 177).

O comércio renovado com as Américas criava mercados, mas as rotas alternativas (lícitas ou ilícitas) também davam força à difusão e incorporação de mercadorias. Já os aliados continentais, para os quais a Grã-Bretanha pagava taxa de importação, revertiam esse pagamento na compra de produtos. Por outro turno, o bloqueio continental forçou o capital a virar-se para dentro, gerando investimentos em ferrovias, canais e portos. Tudo isso alavancava um pequeno crescimento da renda per capita na Inglaterra e um forte crescimento do capital especulativo no continente europeu (NEAL, 1990, p. 16).

Assim, a haute finance propiciava a diversificação do crédito e a variação das mercadorias; em consonância, surgia solo fértil para experiências e concepções acerca do consumo nas partes do Brasil:

16 A recente obra de James Thompson oferece contribuição decisiva para este debate. Segundo o autor, o desenvolvimento da compreensão, pelos agentes de época, sobre o que seria "opinião pública" surgiu na Inglaterra, no final do século XIX, como elemento essencial do próprio sistema político que se formava e, ao mesmo tempo, como expressão das forças sociais. Nesta linha interpretativa, os discursos sobre "consumo público" tornaram-se uma fonte inesgotável de classificação (inclusão e exclusão de pessoas) e formaram, por este motivo, aspecto importante da construção da noção de "opinião pública", antes de 1914. O importante a reter desta obra, assegurados os devidos cuidados com a periodização e com as diferenças espaciais, é a investigação que o autor realiza sobre a entrada do consumo no fiel da balança para a elaboração pública de um pensamento e de práticas políticas. THOMPSON, 2013. 
Poder-se-á enfim objetar que a nossa população por diminuta em território tão vasto não se pode aplicar a fabricas, e outras artes, sendo sua ocupação natural a da agricultura. Dizemos a isto que o consumo anda a par da população, e por conseqüência que nela, seja qual for, existem braços para fabricar as coisas indispensáveis à sua existência; por isso que não aparece no mundo civilizado exemplo de uma nação puramente agrícola sem outra nenhuma indústria, como nos viria a reduzir a imputação amplíssima até daquelas coisas que já temos quem fabrique e que sempre chegam para o nosso consumo (...)

Demonstrando que o comércio da Índia deve ficar privativo a este Reino e a importação estrangeira deve ser limitada (RESPOSTA, 1808, p.12).

A palavra consumo aparece no excerto, pela primeira vez, com a conotação de relação social; já no fím da citação, é utilizada em sua acepção clássica: consumir, tragar. Esta mudança de significado era uma novidade à época. A variação entre a relação social de consumo e a prática de consumir remetia, imediatamente, ao sujeito da ação. Quem consumia? O mesmo documento oferece a resposta: uma "diminuta" população espalhada por um vasto território. Uma vez que os negros, indígenas e livres pobres não eram sopesados, segundo o testemunho de época, a população aparecia como inexpressiva. Diminuta, aqui, é um adjetivo que informa sobre uma distinção. Não se trata de uma quantidade. Logo, um pequeníssimo grupo consumia e teria capacidade para transformar esta ação individual numa relação social (ainda embrionária). ${ }^{17}$ Para o

17 Esta questão já foi esquadrinhada por nossa produção acadêmica. Florestan Fernandes salientou que sem trabalho assalariado e expansão da ordem competitiva, o problema central seria compreender como chegamos a uma economia de mercado de bases capitalistas. Em 
grupo diminuto, os bens chegariam, porque nenhuma nação "civilizada" era completamente agrícola.

Foi neste quadro que novas mercadorias começaram a desaguar nas partes do Brasil. Os bens surgiam como frutos de acordos temporários, importações limitadas ou contrabandos e, nessas condições, cedo adquiriam um caráter de reserva, mesmo que fossem produtos ordinários:

Entre as Nações concorrentes a que mais se há de temer é a Inglaterra, posto que é nossa antiga e fiel aliada e que tão generosa se tem magistrado nas árduas circunstâncias, em que nos achamos, pois que suas embarcações aqui já trazem vestidos feitos de todas as medidas, calçados de todas as qualidades, courama curtida, candeeiros, telhas e tijolos, procurando realizar tudo a dinheiro." (RESPOSTA, 1808, p. 05).

$\mathrm{O}$ que o duro jogo entre aberturas e proteções evidencia além, é claro, dos interesses dos comerciantes privados - é o flagrante momento em que a geração de políticas para circulação de mercadorias não podia mais prescindir de uma percepção política acerca do consumo. ${ }^{18}$

outro artigo clássico, o autor assinala que a especialização colonial, depois da independência, condicionou e se alimentou da preservação e dinamismos coloniais. Já Celso Furtado, reconheceu no descompasso entre produção e consumo interno as causas de um crescimento para fora e estancamento da economia brasileira na primeira metade do século XIX. João Manuel Cardoso vislumbrou essas duas ordens de problemas e salientou que o capitalismo "valeu-se da periferia para rebaixar o custo tanto da força de trabalho quanto dos elementos componentes do capital constante". Cf. FERNADES, 2006, p. 39 e 1976, p. 13.; FURTADO, 1975; MELLO, 2009.

18 Advogamos que o surgimento desta percepção política acerca do consumo marcou o nascimento de uma sociedade de consumo no Brasil. Este tema é bastante polêmico; já que toda Sociedade é uma sociedade de consumo. O fenômeno que se convencionou chamar de sociedade de consumo pela Historiografia - e utilizado neste artigo - está ligado diretamente à contemporaneidade e indica para um momento histórico em que o consumo se tornou uma relação que aglutinava esferas econômica, social e cultural, consubstanciando um novo discurso político. A ênfase também se dá pelas modificações materiais provocadas pela revolução industrial e pela ampliação da circulação de pessoas e de mercadorias. O mais correto seria escrever: Sociedade informada por práticas sócio-econômicas-políticas com predominância do consumo em sua lógica de produção e reprodução. Para simplificar, utilizaremos a terminologia Sociedade de Consumo e procuraremos indicar a historicidade do termo. Recorrentemente, os pesquisadores optam pelo 
As hipóteses e evidências apresentadas neste artigo terão que ser submetidas a investigações em maior escala. Por ora, nossa amostragem indica que o consumo no Brasil surgiu - enquanto relação social - a partir de práticas e concepções que limitaram, desde o princípio, o ato de consumir de boa parcela da população. $O$ resultado mais marcante desta limitação foi que a racionalidade discursiva ${ }^{19}$ negava a existência do próprio consumidor.

O nosso esforço consiste em sopesar o surgimento de uma sociedade de consumo nos pratos da mesma balança das relações diplomáticas, das transformações econômicas e da nova cultura política. Esta tarefa nem sempre tem se mostrado simples, muito embora, o complexo jogo entre acordos, compromissos e disputas tenha nos permitido avançar no debate sobre a manutenção/extinção dos monopólios, à proporção que identificamos a construção de reservas como parte da própria concepção política acerca do consumo, gestada naquele período.

\section{Considerações finais}

A originalidade da transferência de uma corte para a sua colônia, embora não explorada à exaustão, é o pano de fundo sobre o qual se movimentaram os arranjos provisórios e práticas inventadas e reinventadas de circulação das mercadorias.

termo cultura de consumo. Nos dois casos, há pesquisadores que só reconhecem suas validades para o período posterior à Primeira Guerra Mundial.

19 Compreendo por "racionalidade discursiva" a ideia "de que empregamos o predicado 'racional' primordialmente para opiniões, ações e proferimentos linguísticos porque deparamos, na estrutura posicional do conhecer, na estrutura teleológica do agir e na comunicativa do falar, com diferentes raizes de racionalidade. Estas, por sua vez, não parecem ter nenhuma raiz comum, pelo menos não na estrutura discursiva da práxis da fundamentação, nem na estrutura reflexiva da autorreferência de um sujeito participante dos discursos. Parece, antes, que a estrutura discursiva cria correlação entre estruturas ramificadas de racionalidade do saber, do agir, do falar ao, de certo modo, concatenar as raízes proposicionais, teleológicas e comunicativas. Nesse modelo de estruturas nucleares engrenadas umas nas outras, a racionalidade discursiva deve seu privilégio não a uma operação fundadora, mas a uma operação integradora." (grifos do autor). HABERMAS, 2004., p. 101. 
É certo que não estamos falando de todo o problema. Os usos dos objetos ficaram de fora de nossa análise. Elencou-se, apenas, o quadro de disputas entre Grã-Bretanha e Portugal, no período entre 1808 e 1821 e, dentro deste quadro, as linhas que desenharam as práticas do exclusivo e as aberturas comerciais possíveis.

Também optamos por dividir os debates diplomáticos em dois momentos: 1808 e 1814. Contexto inicial dos acordos entre GrãBretanha e Portugal, o primeiro período foi reconhecido como de maior margem à atuação da diplomacia portuguesa. No segundo momento, os Braganças procuraram manter a sua legitimidade por meio do cumprimento dos Acordos de Viena, fazendo uso, ao mesmo tempo, de alguns pontos do Tratado de 1810. Este blefe foi indício de fraqueza, ou, como intuíram as personagens de época, "uma hábil saída a toda ordem de exploração da costa do Brasil" (ROSAS, 1823).

Em todos os casos analisados neste artigo a influência inglesa aparece como importante para o jogo entre dosagens e distensões das leis. ${ }^{20}$ No entanto, houve um duro movimento de resistência da diplomacia portuguesa que sustentou a burocracia de Estado, os monopólios sobre alguns produtos e garantiu a manutenção do império português. ${ }^{21}$ Esta nova realidade contraditória, vivenciada por homens e mulheres estabelecidos nas partes do Brasil, mesclava liberdades e privilégios, normas e decoros e assinalava as absorções possíveis de produtos e de fronteiras comerciais.

Domínios públicos e privados também são tratados como dois lados de uma mesma moeda. Aos agentes de época, todas essas novidades traduziam-se em redirecionamento da própria percepção sobre o futuro, sobre os graus de civilização dos povos e sobre a relação entre avanço material e desenvolvimento econômico, consubstanciando peregrinações de pessoas, circulação de novos objetos e compreensões variadas sobre o comércio e seus agentes. Nesta perspectiva, a dinâmica de Estado, construída no contexto de

20 Arruda reconheceu que o período de crise que envolveu a transferência da corte portuguesa para o Brasil ensejou uma nova política externa por parte da Grã-Bretanha. Para o autor, o bloqueio dos mercados europeus para os comerciantes ingleses foi um rude golpe. O mercado latino-americano poderia suprir essa necessidade imediata por novos consumidores, ainda que fosse como válvula de escape temporária. ARRUDA, 2008, p.24.

21 Trata-se de uma da especificidade do "pensamento público" sobre o consumo como parte de uma tradição portuguesa de cultura comercial. Cf. PEDREIRA, 1994. 
transferência da corte portuguesa para o Brasil, ofereceu suporte à formação de novos espaços públicos, reorientou os domínios privados e favoreceu uma politização crescente da economia, informando sobre a constituição de uma cultura política que absorvia as experiências de consumo como parte de sua "razão de ser".

A produção historiográfica brasileira tem realizado esforços no sentido de compreender o papel dos comerciantes e de suas redes na passagem do século XVIII para o XIX. ${ }^{22}$ Outra ordem de debate tem salientado o alargamento das conexões transoceânicas (CARREIRA, 2005).

Diante desse acúmulo de saberes, cabe o questionamento sobre as práticas de legitimação dessa nova ordem burguesa. Esse viés tira o foco dos comerciantes, ou dos movimentos que gestaram a independência do Brasil e busca reconhecer, numa perspectiva ampla, a especificidade do "pensamento" sobre o consumo como parte de disputas externas e de uma cultura política local e em transformação.

A complexidade da ação diplomática e comercial funcionou com um dos vértices da construção desse novo campo semântico, gerando novas identidades coletivas e forcejando um equilíbrio possível entre domínios públicos e privados. Em face dessas transformações, surgiram condições favoráveis, no Império do Brasil, para que uma parcela da elite se fizesse burguesa. ${ }^{23}$

No estágio atual da produção acadêmica, torna-se importante retomar as perspectivas que assinalam as determinações dos Estados e as liberdades comerciais críveis (LOGEMANN, 2012; ALLEN, 2009). Tudo isso não nos faz voltar para um debate da década de $1980 .{ }^{24}$ Muito pelo contrário, nos permite compreender como surgiram os novos bens artesanais (depois da Revolução Industrial), como se consolidaram as denominações de origem, quais foram os

22 Guimarães tem dedicado infindáveis esforços em compreender a circulação desses comerciantes e suas redes de negócios na primeira metade do século XIX no Brasil. GUIMARÃES, 2012.

$23 \mathrm{O}$ tema da formação burguesa no Brasil é bastante vasto. Não entraremos nesta discussão. Sob qualquer recorte, o texto referência é "A Revolução Burguesa no Brasil"; FERNANDES, 1976. Descobertas recentes têm nos ajudado a escrutinar o momento de separação entre a ordem burguesa e surgimento das classes médias no Brasil. Cf. OWENSBY, 1994.

24 Para Brian Cowan, muito embora as pesquisas tenham andado a passos largos, muito mais há por se fazer: a história de conceitos como compras, bens, e propriedades requerem mais investigação. COWAN, 2012, p. 251-285. 
produtos que ascenderam à escala industrial, para onde foram essas mercadorias, quem as utilizou e como ocorreram esses usos. Para os historiadores do Brasil, este debate está apenas começando.

Neste artigo balizamos as tentativas e erros à construção de um novo universo de mercadorias. Esta construção exigiu o traçado pela primeira vez - de uma percepção política acerca do consumo. Isso não se deu do dia para a noite. Deparamo-nos com linhas constitutivas, e pouco exploradas, desses olhares e práticas sobre o consumo no Brasil, nos tempos da mudança.

\section{Fontes}

CANNING, Jorge. Carta de Jorge Canning para Strangford. Londres: National Archive. FO 63/59. Abril a setembro de 1808.

BRASIL. Coleção de Leis. Carta de lei de 26 de fevereiro de 1810. Ratifica o Tratado de Commercio e Navegação entre o Príncipe de Portugal e El Rey do Reino Unido da Grã-Bretanha e Irlanda. Rio de Janeiro: Imprensa Nacional, 1890. Vol 1., p. 52.

CASTRO, Fernando José de Portugal e. Solicitação para Levar o Navio Inglês Delfim do Porto de São Sebastião. Rio de Janeiro: Arquivo Histórico do Itamaraty, 1815.

FOREING Office. National British Arquive. Londres. FO/63/71, 1809.

LEGAÇÕES Estrangeiras. Arquivo Histórico do Itamaraty. Rio de Janeiro, 285/03/9, 1808.

MISSÕES Diplomáticas. Despachos. Rio de Janeiro: Arquivo Histórico do Itamaraty. Estante 218, prateleira 04, maço 1, folha 103, 1812.

NOTAS Expedidas. Rio de Janeiro: Arquivo Histórico do Itamaraty, 1808-1810.

OFÍCIOS Diversos. Londres, 1822-1823. Rio de Janeiro: Arquivo Histórico do Itamaraty, estante 216, prateleira 1, maço 01. 1822. 
RESPOSTA a Um Aviso, Considerações Sobre Uma Representação com Artigos Referentes ao Comércio com A índia e Outros Países. Rio de Janeiro: Fundação Biblioteca Nacional, Manuscritos, II30,34,022, 1808.

ROSAS, Pedro Luiz. Carta ao Barão Torre de Garcia D'Avila referente ao comércio de Gêneros Agrícolas. Rio de Janeiro, Fundação Biblioteca Nacional, Documento Textual, I- 02, 24, 105, 27/05 de 1823.

SMYTHE, Percy Clinton Sidney. Letters From Rio de Janeiro. Londres: National Archive. FO 63/122. Janeiro a dezembro de 1812.

THE PARLIAMENTARY Debates From the Year 1803 to the Present Time. London: I. C. Hansard, vol. 25, 1808-1821.

\section{Bibliografia}

ALLEN, Robert. The British Industrial Revolution in Global Perspective. Cambridge: Cambridge University Press, 2009.

APPADURAI, Arjun. A Vida Social das Coisas. As mercadorias sob uma perspectiva cultural. Niterói: editora da UFF, 2008.

ARRUDA, José Jobson. A. O Brasil no Comércio Colonial. São Paulo: Ática, 1980. . Uma Colônia Entre Dois Impérios. Bauru: EDUSC, 2008

BAUDRILLARD, Jean. A Sociedade de Consumo. Lisboa: Edições 70, 2008.

BLAUFARB, Rafe. Bonapartists in the Borderlands. Tuscaloosa: The University of Alabama Press, 2005.

BOHRER, Saulo Santiago. Mercado de Seguros Luso Brasileiro: a casa de seguros de Lisboa e do Rio de Janeiro (1758-1831). Tese de doutorado, Rio de Janeiro: UFF, 2012. 
BRIGGS, Asa. História Social de Inglaterra. Lisboa: Presença, 1994. CLAVERÍAS, Belén Moreno. Pautas de Consumo y Diferenciación Social en la Cataluña Preindustrial. Una sociedad en transformación a partir de los inventarios post-mortem. Tese de doutorado, European University Institute, Florencia, 2002.

COWAN, Brian. Public Spaces, Knowledge, and Sociability. In: TRENTMANN, Frank. The Oxford Handbook of History of Consumption. Oxford: Oxford University Press, 2012, p. 251-285.

DE VRIES, Jan. The Industrious Revolution: Consumer Behavior and household economy, 1650 to present. Cambridge: Cambridge University Press, 2008.

FATTACCIU, Irene. Gremios y Evolución de las Pautas de Consumo en el Siglo XVIII: la industria artesanal del chocolate. In: NAVARRO, D. M. Comprar, Vender e Consumir: Nuevas Aportaciones a la historia del consumo en la España moderna. València: Publicaciones de la Universitat de València, 2011, pp. 153-171.

FERNADES, Florestan. A Revolução Burguesa no Brasil. São Paulo: Globo, 2006.

. Circuito Fechado. São Paulo: Hucitec, 1976.

FURTADO, Celso. Formação Econômica do Brasil. São Paulo: Companhia Editora Nacional, 1975.

GUIMARÃES, Carlos Gabriel. A Presença Inglesa nas Finanças e no Comércio no Brasil Imperial. São Paulo: Alameda, 2012.

. O Comittee de 1808 e a Defesa dos Interesses Ingleses com a Corte no Brasil. Anais do XXIV Simpósio Nacional de História. São Leopoldo: UNISINOS, 2007.

HABERMAS, Jürgen. Verdade e Justificação. Ensaios filosóficos. São Paulo: Edições Loyola, 2004.

HECKSHER, Eli. F. La Época Mercantilista. Historia de La Organización y las ideas Económicas desde el final de edad Media Hasta La Sociedad Liberal. México: FCE, 1943. 
HOBSBAWM, Eric. Da Revolução Industrial Inglesa ao

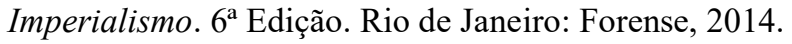

JACOBSEN, Helen. Luxury and Power. Oxford: Oxford University Press, 2012.

LEITE, Rosângela F. Desvios de Rotas. O cotidiano das embarcações no período de transferência da Corte Portuguesa para o Brasil. Saeculum, João Pessoa, nº 27, 2012.

MELLO, João Manuel C. O Capitalismo Tardio. Campinas: Facamp, 2009.

MILlER, Daniel. Trecos, Troços e Coisas. Estudos Antropológicos sobre cultura material. Rio de Janeiro: Jorge Zahar, 2013.

MONTELLEONE, Joana. O Circuito das Roupas. A corte, o consumo e a moda (Rio de Janeiro, 1840, 1889). Tese de Doutorado, São Paulo, USP, 2013.

NAVARRO, Daniel. M. (ed.). Comprar, Vender y Consumir: nuevas aportaciones a la historia del consumo en la Espanã moderna. València: Publicaciones de la Universitat de València, 2011.

NEAL, Larry. The Rise of Financial Capitalism.International Capital Markets in the Age of Reason.Cambridge: Cambridge University Press, 1990.

NEVES, Lúcia Maria Bastos Pereira das. Napoleão Bonaparte. Imaginário e política em Portugal c. 1808-1810. São Paulo: Alameda, 2008.

OLIVEIRA, Milena Fernandes de. Consumo e Cultura Material. Tese de Doutorado, Campinas, Unicamp, 2009.

OWENSBY, Brian. "Stuck in the Middle": Middle Class Society in Modern Brazil, 1850-1950. Yale, Doutorado, Yale University, 1994.

PEREIRA, Gaspar Martins. A região do Vinho do Porto - origem e evolução de uma demarcação pioneira. Estudos \& Documentos, Douro, 1996, vol. 1, p. 177-194.

POLANYI, Karl. A Grande Transformação. As Origens de nossa época. $11^{\circ}$ reimpressão. Rio Janeiro. Elsevier, 2000. 
SCARPELLINI, Emanuella. Material Nation. A consumer history of modern Italy. Oxford: Oxford University Press, 2011.

SCHULTZ, Kirsten. Versalhes Tropical. Império, monarquia e a Corte real portuguesa no Rio de Janeiro, 1808-1821. Rio de Janeiro: Civilização Brasileira, 2008.

SILVA, Maria Beatriz Nizza da. Cultura e Sociedade no Rio de Janeiro, 1808-1821. São Paulo: Companhia Editora Nacional, 1977.

SOUZA, Elizabeth Santos de. S. O Mercado de Créditos na Corte Joanina: experiência das relações sociais de empréstimos (18081821). Dissertação de Mestrado, Rio de Janeiro, UFF, 2015.

STANIFORTH, Mark. Material Culture and Consumer Society. Dependent Colonies in Colonial Australia. Plenun: New York, 2003.

THOMPSON, Edward Palmer. Costumes em Comum: estudos sobre a cultura popular tradicional. São Paulo: Companhia das Letras, 1991.

THOMPSON, James. British Political Culture and the Idea of 'Public Opinion', 1867-1914. Cambridge: Cambridge University Press, 2013.

TRETMANN, Frank. Free Trade Nation. Oxford: Oxford University Press, 2009.

. (org.). The Oxford Handbook of History of Consumption. Oxford: Oxford University Press, 2012.

WALLERSTEIN, Immanuel. El Moderno Sistema Mundial III. La segunda era de gran expansión de la economía-mundo capitalista, 1730-1850. Madrid: Siglo Veintiuno, 1999.

WILlIAMS, Rosalind H. Dream Worlds: Mass Consumption in Late Nineteenth Century France. Berkeley: University of California Press, 1982. 